\title{
Frameworks used in cluttering treatments: Past, present, and future
}

\author{
Judith Felson Duchan* \\ State University of New York at Buffalo, Buffalo, NY, USA
}

Received 7 July 2021

Accepted 25 August 2021

\begin{abstract}
.
BACKGROUND: This integrative review is of two literatures on cluttering treatments. It integrates into those two reviews a third literature to show an alternative way for cluttering to be treated in the future.

OBJECTIVE: The aim is to encourage professionals involved in treating those who clutter to reflect on how conceptual frameworks can affect their treatment choices.

METHODS: Works from three literatures on interventions are examined. Literatures covering two historic periods of cluttering treatments are compared to one another and to a third literature that offers an alternative framework for working with those who clutter.

RESULTS: Treatment approaches to cluttering have almost universally focused on remediating impairments associated with the disorder. This impairment focus flows from a medical model - a model that views cluttering as a disease, located in the person, in need of remediation. An alternative framework, called the social model, one that focuses on the social conditions surrounding cluttering, is reviewed for its applicability to cluttering therapy.

CONCLUSIONS: The medical model, used by authors since cluttering first appeared in the literature, carries within it assumptions about the selection and sequencing of clinical goals aimed at reducing cluttering symptoms. The social model alternative would likely shift the focus to working on ways for promoting the life participation of those who clutter. The applicability of social model practices to the treatment of cluttering is explored and encouraged.
\end{abstract}

Keywords: Cluttering, treatment, frameworks, medical model, social model

\section{Introduction}

Nearly 25 years ago, in 1996, Florence Myers, a leader in the cluttering literature, wrote that our understanding of cluttering is in a pre-paradigmatic stage (Myers, 1996a). She argued that cluttering lacks a clear definition and that it needs better theories and research into its causes and features. She, along with others, also have called for more efficacy studies of

${ }^{*}$ Corresponding author: Judith Felson Duchan, State University of New York at Buffalo, 1 Gates Circle, Apartment 601, Buffalo, NY 14209, USA. E-mail: jaduchan@gmail.com. cluttering treatments (Myers 1996a, see also Craig, 2010). These calls for a better definition, more basic research and efficacy studies of cluttering treatments have continued to the present.

This review takes issue with Myers' premise that the field of cluttering lacks a paradigm. It examines how cluttering theory, research, and clinical practice has been based in an already well-worked out paradigm. Indeed, it will be argued here that it is just such a paradigm that leads to Myers' dissatisfactions with the field. The hope is to show that Myers' and others' depictions of what is needed for the field of cluttering is itself embedded in an overarching 
framework - the medical model. It is the medical model that leads to the portrayal of cluttering as an illdefined disease, whose accompanying impairments or symptoms are in need of efficacious therapies. The very notions of cluttering being a disease, with symptoms in need of therapy are constructs that are born out of circumscribed way of thinking - the medical model.

The medical model's strong influence on past and current therapy practices becomes apparent after examining the history of cluttering treatments. The impact of the medical model becomes even more apparent when those treatments are compared with those that emerge from another framework called the social model. Within the social model, the focus on the interventions shifts from treating impairments within an individual, to the working with the conditions blocking that individual's social participation.

\section{Methods}

This article is an integrative literature review, with a theoretical focus. Its purpose is to present a representative, highly selected literature where the works are used to best illustrate underlying conceptual frameworks that govern cluttering treatments. Integrative literature reviews, such as this one, are designed to generate new knowledge about a topic by reviewing, critiquing, and synthesizing representative literature in an integrated way such that new frameworks and perspectives are brought to bear (Torraco, 2016).

Three of these purposeful literature samplings are examined. One is of an older history of cluttering treatments from late in the 18th century to the mid 20th century, when Deso Weiss published his seminal book on cluttering (Weiss, 1964). This older history includes the treatment approaches of Thomas Sheridan (1762), John Thelwall (1812), Adolph Kussmaul (1877), Raphael Coen (1885), James Sonnet Greene (1916), Emil Froeschels (1946), and Deso Weiss (1964). These authors' writings on cluttering have been written or translated into English, either in part or in full.

A second review of a more recent literature sampling spans mid 20th and early 21 st century therapies. This later body of work starts with works written just after Deso Weiss published his 1964 book on cluttering, an event that has been considered a turning point in the history of cluttering (Myers 1996a; Van
Riper, 1992). After Weiss' 1964 publication, and in part because of it, cluttering moved from its peripheral or "orphan" status in the field to more recent times when it became more recognized (Daly, 1993; Weiss, 1967; see Duchan \& Felsenfeld, 2021)

Writings from the two historical periods were selected from a larger body of work on cluttering treatments. The review is not intended to be exhaustive. Nor is it intended to determine the efficacy of different treatment strategies or methods. Rather the articles were picked to show how conceptual frameworks have influenced cluttering treatment across time. Excluded were works that fell outside the themes of this essay and ones that were not easily accessible. Works in other languages that were not translated or published in English were not reviewed. There were other works, too many to cover, that reinforced the findings of this review.

A third literature was added to this paper after the first two reviews were concluded. It examines works that have been framed from within a social model. Social model practices were not present in any of the cluttering treatment literature under review nor in the cluttering treatment literature from which the review articles were sampled. This third review, therefore, went beyond the literature on cluttering to find examples of how the social model has been applied to other communication disorders. Comparisons between the social model and medical model practices were made to show the crucial role that frameworks can play when designing and carrying out cluttering treatments.

The selection of relevant articles on cluttering treatments was pulled from citations (e.g., Weiss, 1964), annotated bibliographies (e.g., Meyers, 1996b) and Google searches (Google Scholar). Particular works were selected that represented various decision points in designing and carrying out cluttering treatments. Those points occurred when authors made decisions about (1) what to target for therapy, (2) how to sequence their therapy targets, (3) how to tailor their therapy to fit individual needs, and (4) what methods or activities to use to achieve the therapy goals. Treatment decisions such as these four are compared within and across the two historical periods. Examples of treatment approaches from a third literature, one carried out under the social model, were also analyzed and compared with those used in the cluttering literature. They were selected as illustrations of different ways treatments have been designed from within the social model. 


\section{Results}

Since the late 1800 s, researchers and practitioners writing about cluttering treatments have focused primarily on how to minimize or eliminate impairments associated with the disorder. In so doing, they have been met with several decision points. One is to figure out what impairment to work on first. Another has involved how best to sequence therapies aimed at different impairment domains. Clinicians who have aimed at crafting their therapies to fit individuals' impairment profiles have faced a third issue-how best to individualize their treatment program. Lastly, once an impairment domain has been targeted, clinicians need to design specific therapy methods for ameliorating that impairment.

\subsection{Therapy approaches before 1964}

Articles on cluttering treatment often contain lists of impairment domains affected by cluttering, sometimes those same domains that serve as defining criteria for diagnosing cluttering (Weiss, 1964). Clinicians and researchers who have designed therapy to minimize or eradicate impairments of cluttering are therefore faced with decisions about what in the long list of impairments to target and in what order.

Deso Weiss offered two general strategies for selecting therapy targets:

(1) the symptomatic treatment of every area of failure, and (2) the intention of striking the core of cluttering by treating the weakness of concentration and attention. Detailed descriptions of therapeutic progress would facilitate a decision between these two alternatives (Weiss, 1967, p. 255).

In his symptom-based approach, Weiss recommended working on no more than two areas of impairment at a time (Weiss, 1964, p. 81). He suggested first targeting the most problematic areas of cluttering for a particular person. "The therapist should ask himself constantly what element in the clinical picture seems most disturbing or in most urgent need of correction" (Weiss, 1964, p. 80). Weiss believed that the most problematic areas will change as therapy progresses and recommended that the therapy targets be changed accordingly.

Some specialists focused first on working to eliminate the cause of cluttering. Emil Froeschels, a researcher and clinician practicing in Vienna and then
America, advocated teaching the phonetic alphabet to those who clutter. This treatment was to take care of the person's "acoustic inattentiveness", a factor he felt caused cluttering. His specific treatment was to teach the distinctive features of individual sounds so as to help the patient control the accuracy and tempo of his articulation (Froeschels, 1946).

James Sonnett Greene, an early speech pathologist and physician practicing in New York City, promoted several kinds of causally-based therapies for his patients diagnosed with agitophasia, his name for cluttering (Greene, 1924). He saw agitophasia as being a "nervous condition" and therefore focused some of his "medical" remedies on "calming the nerves".

A child suffering from it (cluttering) should, of course, receive medical treatment for his nerves; but it here may be said that for nervous children of all kinds, including those who stutter, there usually are few things so beneficial as plenty of life in the open air (1924, p. 696).

Greene also recommended applying electric currents to those who clutter to stimulate their nerve and muscle activity (Greene, 1916, p. 757), another of his approaches designed to minimize nervousness and thereby treat the cause of cluttering. He referred to this method as "faradism". (See Basford 2001 for a history of electrical treatments used during Greene's time.)

Other writers have based their choice of what to prioritize in therapy on a logical understanding of a relationship between the targeted impairment and the other impairments associated with cluttering. For example, it has been argued that a person must first see themselves as having a speech problem in order for them to be motivated to change their speech in other ways (Weiss, 1964). Such a lack of awareness has been frequently reported to be a problem endemic to cluttering (Kussmaul, 1877; Weiss, 1964; Daly \& Burnett-Stolnack 1995; Bakker \& Myers, 2011; Duchan \& Felsenfeld, 2021).

Methods for increasing clients' awareness of their cluttering have involved direct explanation and imitation of the clutterer in their presence to point out the need for change. After the advent of tape recorders, clients were asked to listen to their own speech in order to become aware of its defective nature (Weiss, 1964 , p. 80). Awareness training has also been consisted of pointing out the features of better speech and then modeling and practicing it (Kussmaul, 1877, p. 818; Weiss, 1964, p. 80). Kussmaul, a 19th century 
German physician who specialized in speech disorders, recommended:

[...] explaining to the patient, the cause of his defective speech, exhorting him to think and speak quietly, and accustoming him by means of recitations, declamations, and methodically conducted conversations to think in a measured style and to place and articulate his words properly (Kussmaul, 1877, p. 818).

Most early writers designed therapies to slowing down the rate of speech of people who clutter. Thomas Sheridan, an 18th century British elocutionist, had his students read aloud at a slower rate that they were used to with attention to rate rather than meaning:

[... ] to lay aside an hour every morning, to be employed in the practice of reading aloud, in a manner, much more slower than is necessary. This should be done in the hearing of a friend or some person whose office it should be to remind the reader if at any time he should perceive him mending his pace and falling into his habit, of a quick utterance. Let him sound all his syllables full, and have that point only in view, without reference to the sense of the words, for if he is attentive to that, he will unwarily fall into his old habit [... ] (Sheridan, 1762, p. 27).

In 1885, Raphael Coen, a physician practicing in Vienna, Austria, promoted a therapy in which his patients read aloud slowly while at the same time emphasizing the rhythmic qualities of the passages, a method he called "reading gymnastic":

[... The patient should be directed to declaim a sentence in musical measure... it is necessary that the reading proceed in a very slow measure and in the beginning only five or six sentences should be practiced, but they should be repeated until they are produced without any blemish [... ]. Such reading-gymnastic should be taken daily from thirty to forty minutes $[\ldots]$. As soon as the patient can read well, he should commit to memory poems [... ]. After exercising by reading poetry, prose should be taken (Coen, 1885, p. 56-57).

John Thelwall (1812) and Deso Weiss (1964), also used oral recitation of poetry as an avenue to teach the rhythmic qualities of speech and language. Thelwall had normal and abnormal speakers work on rhythms to improve their elocution and intelligibility (Thel- wall, 1812). Weiss recommended having people who clutter memorize poems with strong rhythms to "help give speech a rhythmic flow" (Weiss, 1964, p. 91).

James Sonnett Greene worked on reducing speed by coaching his patients to speak in a slower, more deliberate way:

In a quiet way, repeated efforts should be made to slow his speech down, and to teach him to have clearly in mind what he wishes to say before he attempts to say it, and then to say it slowly and deliberately (Greene, 1924, p. 696).

Still other early therapy techniques designed to slow speech rate include syllable tapping during speech (Weiss, 1964, p. 82), pronouncing syllables in words and in sentences one at a time (Weiss, 1964, p. 82), and exaggerating accentuation of stressed syllables during spontaneous speech (Sheridan, 1762, p. 27; Weiss, 1964, p. 89).

A common reaction to cluttered speech by listeners has been to ask the person directly to slow down their rate. However, such requests, or "exhortations" as Weiss has described them (Weiss, 1964, p. 83), have been reported to be an ineffective approach to treatment (Weiss, 1964, p. 83; Van Riper, 1992, p. viii; St. Louis et al, 2003).

In sum, therapy suggestions in the literature up to 1964 focused on how to select and sequence impairments to work on. Once an area was identified, authors described methods they had found useful for improving performance in that area. Priorities were given to impairment areas that were thought to cause cluttering as well as ones that were thought to be the most impacting. Considerable attention, throughout this older historical period, was on therapies to increase a person's self-awareness of their cluttering as well as therapies to decrease speech rate. Practitioners described the methods they used to minimize these identified impairments.

\subsection{Therapy approaches after 1964}

The treatments since 1964 have continued focus on minimizing or eliminating problems associated with cluttering. Authors, in this second historical period also have been concerned about how to select what to work on from a list of presenting symptoms (St. Louis, et al, 2007; St. Louis \& Shulte, 2011; Lanouette, 2011; see Duchan \& Felsenfeld, 2021).

Florence Myers, whose work plays a central role in today's cluttering literature, has promoted a small list of impairments that she casts as the most essential 
to remediate cluttering (Myers, 1992, p. 181). Her choice of what to work on first is based on the hopedfor generalizability of the first areas targeted (Myers, 1992, St Louis, et al, 2007). The selected targets are sometimes confined to those impairments that make up cluttering's "the lowest common denominator" (St. Louis, 1992; St. Louis et al., 2003; St. Louis et al, 2007 St. Louis \& Schulte, 2011).

Elsewhere Myers favors increasing self-awareness of cluttering as the first step in cluttering therapy:

It is important to confer with the PWC regarding self-awareness not only during the initial evaluation but throughout treatment, as this skill is an essential first step to effect behavioral change. A primary goal in therapy, therefore, is to improve the client 's awareness of relatively cluttered vs. less cluttered speech (Myers, 2007, p. 112).

Methods for achieving awareness of one's own cluttering symptoms have involved using negative practice, where people are asked to replicate their own cluttered speech (Myers, 2011, p. 161), working with people to analyze aspects of their own speech (Daly,1992), and having those who clutter monitor other people's reactions to their impaired speech (Lanouette, 2011, p. 195; Myers 2011, p. 161).

Authors since Weiss (1964), just like those of earlier times, have often selected rate as an early target of impairment. Slowing one's speech rate has been considered a good first or second goal because it will give the client more "processing space" that can be applied in other domains, such as language formulation and discourse organization. A brochure on cluttering published by The Stuttering Foundation contends that: "Many cluttering symptoms are often reduced if the clutterer can achieve a slower rate that is more in line with what their system can handle" (St. Louis \& Scaler Scott, 2021).

Recent authors have argued that slowing down speech rate has the potential of improving other areas of cluttering, such as regularizing timing, improving articulation, decreasing excess co-articulation, and organizing language and thought processes (Myers 1992; Myers \& Bradley, 1996). This effect of improvement in one area on other areas is what Myers and colleagues have called synergy (Myers, 1992; Myers \& Bradley, 1996)

Rate control techniques in this later literature have employed deliberate pausing (Simkins, Kingery \& Bradley, 1970; Scaler Scott, et al. 2007; Scaler Scott, Ward, \& St. Louis, 2010; Daly, 2010; Healey, Nelson, \& Scaler Scott, 2015), syllable tapping, (Van Zaalen
\& Reichel, 2014), exaggerated articulation (Healey, Nelson, \& Scaler Scott 2015), delayed auditory feedback (St. Louis, et al. 1996), and matching ones rate to a model (Daly, 1986, 1992, 1993).

Some authors have offered a therapy protocol that lays out a list of impairments to address, in a specified order. This ordering works like a school curriculum, in which preselected topics or subjects, in this case impairments, are covered over the course of treatment. Van Zaalan and Reichel (2014) recommend four such sequential phases for cluttering therapy: symptom self-identification; speech rate reduction, monitoring errors and promoting narrative skills.

Yet another approach for selecting impairment targets for cluttering intervention is to confine therapy to those areas that are most problematic for a particular person. Experts have recommended this individualized approach "since there are few data available suggesting standard procedures for treatment" (St. Louis et al., 2003).

Miyamoto (2011) tailored her therapies to her clients' profiles. She designed two different therapies for two different Japanese speakers who were both diagnosed as clutterers. Similarly, Lanouette (2011) recommends picking targets based on "differential diagnosis and establishment of an individualized treatment plan for each client" (Lanouette, 2011, p. 184). She individualized treatment by first selecting a general domain of cluttering (one of five) that the person has difficulty with, and then designing interventions to fit the particular problems the person has within the selected domain. The five domains are: cognition, language, pragmatics, speech and motor disorders (Lanoutte, 2011, p. 184-5).

Still others recommend fitting the therapy to an individual's cluttering profile as measured by a rating scale. This individualized approach has made use of recently developed assessment checklists wherein a list of cluttering impairments is provided and the therapist checks off the ones their client exhibits. Therapies are designed to fit the individual client profile as shown on the checklist (e.g., Daly \& Burnett-Stolnack, 1995; Daly \& Burnett, 1999). The authors of one such checklist, the Cluttering Severity Instrument, recommend selecting those dimensions in the checklist that impact most on the client's judged cluttering severity (Baker \& Myers, 2011)

To recap, the focus of treatments since 1964, like the treatments before them, have been to minimize or eliminate selected impairments associated with cluttering. Some programs have recommended that one area be worked on first, in hopes that improvement 
in that area would generalize to other areas. Other programs recommend working on several key areas all at once. Regardless of their impairment focus, nearly all treatments, throughout both periods of history, have located cluttering impairments in the individual and have been designed and executed by clinicians with the hope of minimizing or eliminating the impairments. These impairment-based features are characteristic of what has been called "the medical model" of clinical practice.

A summary of the selected medical approaches to cluttering treatments is depicted in Table 1. As can be seen from the left-hand column, writers in both historic periods center their treatments on remediating impairments within the individual. Their concerns are what impairments remediate and in what order. Where the writers in the two historic periods differ has to do do with specific methods used to remediate those impairments, especially when using technology. For example, pre 1964 approaches included "faraday" interventions, post 1964 approaches used audio/video feedback and delayed auditory feedback.

\section{Social model approaches}

There is an alternative to the medical model, a framework that draws directly from the disability rights movement of the 1990s (e.g., Oliver, 1992; Barton, 1996). It has been called the social model.

The social model regards communication disabilities as a function of social conditions rather than regarding them solely as impairments located in the person. Indeed, the social model makes a distinction between impairments (deficiencies in the person) and disabilities (disadvantages resulting from the impairments) (Goering, 2015). Cluttering, in this social model view, is a difference that can lead to a disability of being socially marginalized. The disability of a person is often due to physical, structural, or cultural barriers above and beyond their impairment. The barriers are often seen by social model proponents as more debilitating than the impairment itself. Therefore, the primary focus of treatment in the social model is on reducing barriers and increasing access; that is, reducing the disabling effect of the

Table 1

Historical and Current Applications of the Medical Model to Cluttering Treatments

\begin{tabular}{lrr}
\hline Strategies for & Pre 1964 & Post 1964 \\
Impairment-Based & & \\
Treatments &
\end{tabular}

Select areas of impairment for treatment
Work on nervousness: (1) calm the nerves (Greene, 1924), (2) electrical currents (Greene 1924)
(1) Choose from a preselected set of impairment domains (Daly \& Burnett, 1999; Myers 1992);

(2) Work within domains associated with the "lowest common denominator" definition of cluttering (St. Louis, 1992); (3) Work on a domain that impacts other domains (synergy), e.g., rapid speech (Myers \& Bradley, 2006)
Progress through a sequence of treatments to remedy different kinds of cluttering impairments
Work on no more than two areas at a time. Cycle back when needed (Weiss, 1964)
(1) Work with five preselected dimensions simultaneously (Daly and Burnett, 1999); (2) Sequence lessons for preselected dimensions over different sessions (Van Zaalan \& Reichel, 2014)

\begin{tabular}{lll}
\hline $\begin{array}{l}\text { Tailor treatments to an } \\
\text { individual's impairment } \\
\text { profile }\end{array}$ & $\begin{array}{l}\text { Target the most problematic areas for the } \\
\text { individual first (Weiss, 1964) }\end{array}$ & $\begin{array}{l}\text { Select impairments from the assessment profile } \\
\text { that are most problematic for the person } \\
\text { (Miyamoto, 2011; Lanoutte, 2011) }\end{array}$ \\
$\begin{array}{l}\text { Design Treatments to slow } \\
\text { rate }\end{array}$ & $\begin{array}{l}\text { 1) Have person read aloud slowly (Coen, 1885); } \\
\text { (2) teach speech rhythms (Thelwall, 1816; } \\
\text { Greene, 1924); (3) have client pronounce each } \\
\text { syllable; (4) have client use exaggerated } \\
\text { accenting, syllable tapping, (Weiss, 1964) (5) } \\
\text { mimic person's rapid speech; (6) have person } \\
\text { listen to tapes of his or her recorded speech } \\
\text { (Weiss, 1964) }\end{array}$ & $\begin{array}{l}\text { Have person use delayed auditory feedback (St. } \\
\text { Louis et al., 1996); Have person insert pauses in } \\
\text { sentences (Healy, Nelson, Scott, 2015). }\end{array}$ \\
& $\begin{array}{l}\text { (1) Clinician mimics person's speech; (2) client } \\
\text { listens to recordings of his or her own speech } \\
\text { (Weiss, 1964) }\end{array}$ & $\begin{array}{l}\text { (1) Have clients listen to video/audio tapes of } \\
\text { their own speech (Daly, 1992); (2) Have clients } \\
\text { monitor others' reactions to their cluttered } \\
\text { speech (Myers, 2011) }\end{array}$ \\
$\begin{array}{l}\text { Treatments to increase a } \\
\text { person's awareness of a } \\
\text { cluttering problem }\end{array}$ & &
\end{tabular}


impairment. Its aim is to increase a person's social and communication access to specific everyday life situations, and to give the person a strong voice in the process.

The social model has been adapted for use in a variety of fields of communication disorders resulting in dramatic shifts in the way services have been rendered and delivered in those areas (see Duchan, 2001 for an overview). These fields have included aphasia, intellectual disabilities, augmentative and alternative communication (AAC), and stuttering.

In the field of aphasia, for example, the social model has led to interventions such as training the conversational partners of people with aphasia (Kagan, 1998); facilitating a person's communication access to organizations (Duchan, et al, 2006; Pound et al., 2007); and designing approaches to enhance a person's meaningful participation in selected areas of their lives (LPAA Project Group, 2000; SimmonsMackie, 2000). An example of the partner training is to have partners make available visual material such as maps, pictures, and drawings to add supportive context to conversational interactions with people with aphasia (Kagan, 1998).

Personal Futures Planning is another intervention approach derived from a social model schema. Its use has been primarily with those who have severe communication disabilities. The emphasis of this planning program is to help a "focus person" create and progress along a life plan. The life plan is devised by a team of people in the "relationship circle" of the focus person's. The focus person should be the one who chooses the people in the circle and the life goals to aim for. The goals are about what the person wants to accomplish in life, rather than about reducing their impairment symptoms (Forest \& Lusthaus,1990; Forest \& Pearpoint, 1992).

The social model has also been used to attain school inclusion for those with severe communication impairments (Jorgensen, McSheehan \& Sonnenmeier, 2010). The Beyond Access approach, for example, uses a team of family members and school personnel to determine the supports needed for students to be able participate in classrooms. The presumption of Beyond Access is that all students are competent if they are given the supports they need. With such support, they can become literate, and can learn the same academic content as their peers. This social model practice involves a team of school personnel who tailor classroom supports to work with the targeted student to achieve full and meaningful classroom participation.
Another social model approach has been called The Participation Model, one designed for users of augmentative and alternative communication (AAC) systems (Beukelman \& Mirenda, 2013). Examples of the Participation Model's interventions are ones that adapt the environment and AAC devices to meet the users' communication needs. Other interventions in this model are aimed at reducing "opportunity barriers," barriers that are imposed on the AAC user by outside sources such as restrictive school or employment policies or by low expectations from service providers and/or family members. The aims of the Participation Model are to provide AAC users with opportunities for community living, inclusive schooling, and integrated employment.

There have been some recent applications of the social model to stuttering that offer possible parallels for considering social model use in treating cluttering (St. Pierre, 2012; Tetnowski, 2014; Bailey, Harris, \& Simpson, 2015; Simpson, 2016; Richter \& St. Pierre, 2021). Some authors, for example, have stressed the importance of self-determination in designing support programs for stuttering, and have argued for stuttering to be treated as a product of the discourse between communication partners, not as disfluencies produced by one person. They have also pointed out that normal speech should not be idealized as free of hesitancy and have argued for the importance of advocacy to reduce the stigmatizing impact of non-fluent speech.

The blog called "Did I stutter?" focuses on advocacy and changing negative attitudes about nonfluency, as is expressed in their credo:

Did I Stutter is not a self-help group per se. Rather, we seek to create a space for community, art, and discussion where stutters and other speech dysfluencies can be rethought in affirming ways. In the short-term, we will engage in conversations with other speech-disabled individuals to question our tendency to loath our stutters. We will work actively to challenge assumptions about speech-disability and work to open a conversation about how much of the anxiety related to dysfluency is produced by oppressive social structures and values (Richter \& St. Pierre, 2021).

The social model, when applied to these various areas of practice, while differing in their detail, have striking commonalities. They all emphasize goals and practices aimed at promoting agency and meaningful social participation. They approach their goals by reducing disabling barriers to a person's participation 
in everyday life events and by providing needed support for that person to access those events. Their focus is not on the impairment itself, but the social response to it.

The particular domains targeted in the social model include social participation, life participation, inclusive schooling, integrated employment, and social engagement. The methods for achieving the goals within the various domains include supporting conversation, supporting classrooms, supporting school personnel, joining self help groups, presuming competence, advocating to reduce stigmatization and marginalization, team training, and creating plans that are stepping stones to achieving life participation and longer term life goals. The professional serves as a facilitator or coach, rather than as a clinician. They are in equal partnership with those who solicit support. And social model interventions tend to take place in real-life contexts (schools, homes, museums) rather than clinics or hospitals, or speech therapy rooms.

See Table 2 for a display of different kinds of social model treatments extrapolated from the literature outlined above.

The application of social model practices to cluttering would be tailored to the particular barriers and access needs associated with the person's cluttering impairment. These applications would be designed to take aim at different levels of social interaction and participation, including dyadic interactions, social situations, and culturally-based stigmatizing situations. The likely participants in social model treatments would be the focus person who clutters, the facilitator, and a support team.

Uses of the social model techniques to design treatments with those who clutter are virtually nonexistent (Scaler Scott \& St. Louis, 2011). A possible exception is a self-help advocacy group developed by Joseph Dewey in the late 1990s (Dewey, 2005). However, the advocacy work of Dewey and his webbased Yahoo group is framed within medical rather than the social model constructs. That is, the group has promoted the need for diagnosis of cluttering, for identification of cluttering symptoms and for impairment style speech therapy. There is little effort by Dewey or his colleagues to address issues of stigma or barriers associated with the impairment or to create better access for those who clutter. This is strikingly different from the DidIStutter advocacy blog of Richter and St. Pierre (2021). Dewey's group does fit the social model in one respect, however. It provides a venue for people who clutter

Table 2

Possible Applications of the Social Model to Cluttering

\begin{tabular}{|c|c|c|c|}
\hline $\begin{array}{l}\text { Strategies for Social } \\
\text { Model Treatments }\end{array}$ & Dyadic Interaction & Everyday Events & Cultural Context \\
\hline $\begin{array}{l}\text { Identify barriers to } \\
\text { access }\end{array}$ & $\begin{array}{l}\text { Client and facilitator work } \\
\text { together to identify and } \\
\text { analyze communication } \\
\text { breakdowns during } \\
\text { dyadic interactions. }\end{array}$ & $\begin{array}{l}\text { Client and facilitator trace a } \\
\text { person's social access (and } \\
\text { barriers) to everyday life } \\
\text { events. }\end{array}$ & $\begin{array}{l}\text { Work with communities to reduce } \\
\text { instances of ostracization, bullying, or } \\
\text { low expectations toward people who } \\
\text { clutter. }\end{array}$ \\
\hline $\begin{array}{l}\text { Provide } \\
\text { communication } \\
\text { support }\end{array}$ & $\begin{array}{l}\text { Client and facilitator train } \\
\text { conversational partners to } \\
\text { facilitate communication } \\
\text { with person who clutters. }\end{array}$ & $\begin{array}{l}\text { (1) Client and facilitator ease } \\
\text { understanding of cluttered } \\
\text { speech by making available } \\
\text { supports such as pictures or } \\
\text { key words that can be pointed } \\
\text { to during events. (2) Events } \\
\text { are structured to promote full } \\
\text { participation by all. }\end{array}$ & $\begin{array}{l}\text { (1) Client and facilitator create self-help } \\
\text { support groups; (2) Support team and } \\
\text { clients train affiliates to presume } \\
\text { competence of those who clutter; (3) } \\
\text { Support team and clients promote life } \\
\text { participation and personal futures } \\
\text { planning for person who clutters. }\end{array}$ \\
\hline $\begin{array}{l}\text { Improve access to life } \\
\text { events for person who } \\
\text { clutters }\end{array}$ & $\begin{array}{l}\text { Support team works with } \\
\text { client to identify and } \\
\text { remove barriers to } \\
\text { successful dyadic } \\
\text { communication }\end{array}$ & $\begin{array}{l}\text { Support team works to } \\
\text { remove situational barriers } \\
\text { and create opportunities to } \\
\text { participate in everyday events }\end{array}$ & $\begin{array}{l}\text { Support team works to identify and } \\
\text { eliminate exclusionary practices and } \\
\text { stigmatizing situations that occur in the } \\
\text { culture (e.g., art museums, media), }\end{array}$ \\
\hline $\begin{array}{l}\text { Advocate for } \\
\text { disability rights with a } \\
\text { focus on cluttering }\end{array}$ & $\begin{array}{l}\text { Create social partnering } \\
\text { between support team and } \\
\text { person who clutters to } \\
\text { point out to others the } \\
\text { social barriers to } \\
\text { successful interpersonal } \\
\text { communication }\end{array}$ & $\begin{array}{l}\text { Support teams establish } \\
\text { social rules with affiliates that } \\
\text { foster inclusionary practices } \\
\text { in everyday events. Teams } \\
\text { and focus person provide } \\
\text { training to others to increase } \\
\text { access to everyday events }\end{array}$ & $\begin{array}{l}\text { Those who clutter create and offer } \\
\text { community awareness programs about } \\
\text { disabling conditions affecting those who } \\
\text { clutter. }\end{array}$ \\
\hline
\end{tabular}


to garner social and emotional support from one another.

\section{Discussion}

The treatments of cluttering have since their earliest beginnings been influenced by medical-model thinking. They have been focused on identifying and remediating problems associated with the disorder and viewed as being located within the individual. The specific way the medical model has been implemented has varied some over the years, yet the model itself has held constant. Dissatisfaction with how the medical model serves the field of cluttering has involved calls for better definitions, better basic research, and better efficacy studies. None of these calls involve a shift away from the medical model. They all continue to presuppose that better depictions and treatments for cluttering will involve continued implementation of the medical model.

An alternative to the medical model has become available to practitioners of speech-language pathology since the advent of the disability rights movement in the 1990s. Called the social model, the alternative involves facilitators or support teams working with a "focus person" to target and minimize disabilities associated with their impairment and to facilitate their communication in everyday contexts. The social model would regard problems associated with cluttering as having more to do with barriers to social access and life participation than with an individual's communication impairment. The treatment emphasis in the social model would be on working with the person who clutters to identify and improve their social access and acceptance in dyadic communication, in everyday events, and in the culture.

\section{Acknowledgment}

This article is an extension of another work about the history of cluttering, that one co-authored with Susan Felsenfeld. That companion paper was on how cluttering came to be named, classified, defined, and diagnosed. For this article Sue served as both a sounding board and creative advisor.

\section{Conflict of interest}

The author has no conflict of interest to report.

\section{References}

Bailey, K., Harris, J., \& Simpson, S. (2014). Stammering and the social model of disability: Challenge and opportunity. [Conference presentation] The 10th Oxford Dysfluency Conference, Oxford, United Kingdom.

Bakker, K. \& Myers, F. (2011). Instruction Manual for the Cluttering Severity Instrument. https://associations. missouristate.edu/ICA/Resources/Resources\%20and\%20Lin ks\%20pages/CSI\%20software\%20ALL/CSI\%20Manual_EN. pdf

Barton, L. (Ed.). (1996). Disability and society: Emerging issues and insights. Longman Publishing.

Basford, J.R. (2001). A historical perspective of the popular use of electric and magnetic therapy. Archives of Physical Medicine and Rehabilitation, 8(2), 1261-1269. https://doi.org/ 10.1053/apmr.2001.25905

Beukelman, D., \& Mirenda, P. (2013). Augmentative and alternative communication: Supporting children and adults with complex communication needs. Brookes.

Coen, R. (1885). Cluttering. The Voice, (trans.) 7(4), 56-57.

Craig, A. (2010). The importance of conducting controlled clinical trials in the fluency disorders with emphasis on cluttering. In K. Bakker, I. Raphael \& F. Myers (eds.) Proceedings of the First World Conference in Cluttering. Katarino, Bulgaria (pp. 220-229).

Daly, D.A. (1986). The clutterer. In K. O. St. Louis (Ed.) The atypical stutterer: Principles and practices of rehabilitation (pp. 155-192). Academic Press.

Daly, D. (1992). Helping the clutterer. Therapy considerations. In F. Myers \& K. O. St. Louis (Eds.), Cluttering: A clinical perspective (pp. 107-124). FAR Communications. (Reissued in 1996 by Singular Press).

Daly, D. (1993). Cluttering: The orphan of speech-language pathology. American Journal of Speech-Language Pathology, 2(2), 6-8. https://doi.org/10.1044/1058-0360.0202.06

Daly, D. (2010). Treating cluttering: The power of the pause. International Cluttering Online Conference. http://www.mnsu. edu/comdis/ica1/papers/nuggets/dalyc.html

Daly D., \& Burnett-Stolnack M. (1995). Use of Cluttering Checklist and Profile Analysis in planning treatment for cluttering clients. In C. W. Starkweather \& H. F. M. Peters (Eds.), Stuttering: Proceedings of the First World Congress on Fluency Disorders. International Fluency Association. Nijmegen, The Netherlands: University Press.

Daly, D., \& Burnett, M. (1999). Cluttering: Traditional views and new perspectives. In R. F. Curlee (Ed.), Stuttering and related disorders of fluency (2nd ed.) (pp. 222-254) Thieme Medical Publishers.

Dewey, J. (2005). My experiences with cluttering. International Stuttering Awareness Day Online Conference. http://www. mnsu.edu/comdis/isad8/papers/dewey8.html

Duchan, J. (2001). Impairment and social views of speechlanguage pathology: Clinical practices re-examined. Advances in Speech-Language Pathology, 3(1), 37-45. https://doi.org/ 10.3109/14417040109003707

Duchan, J., \& Felsenfeld, S. (2021). Cluttering framed: An historical overview. Advances in Communication and Swallowing, 24(2), 75-85. https://doi.org/10.3233/ACS-210029

Duchan, J., Jennings, M., Barrett, R., \& Butler, B. (2006). Communication access to the arts. Topics in Language Disorders, 26(3), 210-220. 
Forest, M., \& Lusthaus, E. (1990). Everyone belongs with MAPS action planning system. Teaching Exceptional Children, 22, 32-35. https://doi.org/10.1177/00400599900220 0210

Forest, M., \& Pearpoint, J. (1992). Families, friends, and circles. In J. Nisbet (Ed.) Natural supports in school, at work, and in the community for people with severe disabilities. (pp. 65-860). Paul H. Brookes.

Froeschels, E. (1946). Cluttering. Journal of Speech Disorders, 11, 31-33. https://doi.org/10.1044/jshd.1101.31

Goering, S. (2015). Rethinking disability: The social model of disability and chronic disease. Current Reviews in Musculoskeletal Medicine, 8(2), 134-138. https://doi.org/10.1007/s12178015-9273-z

Greene, J. (1916). Agitophasia associated with agitographia. Medical Record, 90, 754-757.

Greene, J. (1924). Your child's speech. Hygeia. 2, 693-696.

Healey, K., Nelson, S., \& Scaler Scott, K. (2015). A case study of cluttering treatment outcomes in a teen. Procedia: Social and Behavioral Sciences, 193, 141-146. https://doi.org/10.1016/j.sbspro.2015.03.253

Jorgensen, C., McSheehen, M., \& Sonnenmeier, R. (2010). The Beyond Access model: Promoting membership, participation, and learning for students with disabilities in the general education classroom. Paul H. Brookes.

Kagan, A. (1998). Supported conversation for adults with aphasia: Methods and resources for training conversational partners. Aphasiology, 12(9), 816-830. https://doi.org/ $10.1080 / 02687039808249575$

Kussmaul, A. (1877). The defects of speech, dysphrasias. In H. Ziemssen (Ed.) Cyclopaedia of medicine. Trow's Printing and Bookbinding Company.

Lanouette, E. (2011). Intervention strategies for cluttering disorders. In D. Ward \& K. Scaler Scott (Eds.), Cluttering: A handbook of research intervention and education. (pp. 175197). Psychology Press.

LPAA Project Group (2000). Life participation approach to aphasia: A statement of values for the future. ASHA Leader, 5, 4-6. https://doi.org/10.1044/leader.FTR.05032000.4

Miyamoto, S. (2011). Assessment and intervention of Japanese children exhibiting possible cluttering. In D. Ward \& K. Scalar Scott (Eds.), Cluttering: A handbook of research, intervention and education (pp. 198-210). Psychology Press.

Myers, F. (1992). Cluttering: A synergistic framework. In F. Myers \& K. St. Louis (Eds.), Cluttering: A clinical perspective (pp. 71-84). Far Communications (Reissued in 1996 by Singular Press).

Myers, F. (1996a). Cluttering: A matter of perspective. Journal of Fluency Disorders, 21(3), 175-185. https://doi. org/10.1016/S0094-730X(96)00021-6

Myers, F. (1996b). Annotations of research and clinical perspectives on cluttering. Journal of Fluency Disorders, 21(3), 187-199. https://doi.org/10.1016/S0094-730X(96)000 22-8

Myers, F. (2007). Primacy of self-awareness and modulation of rate in the treatment of cluttering. In K. Bakker, L. Raphael, $\&$ F. Myers (Eds.), Proceedings of the First World Conference on Cluttering. Katarino, Bulgaria (pp. 108-114).

Myers, F., \& Bradley, C. (1996). Clinical management of cluttering from a synergistic framework. In F. Myers and K. St. Louis (Eds.), Cluttering: A clinical perspective. Singular Publishing Group.
Oliver, M. (1992). Changing the social relations of research production. Disability, Handicap, \& Society, 7(2), 101-115. https://doi.org/10.1080/02674649266780141.

Pound, C., Duchan, J., Penman,T., Hewitt, A., \& Parr, S. (2007). Communication access to organisations: Inclusionary practices for people with aphasia. Aphasiology, 21(1), 23-38. https://doi.org/10.1080/02687030600798212

Richter Z., \& St. Pierre J. (2014). Did I stutter? https://www. didistutter.org/.

St. Louis, K. (1992). On defining cluttering. In F. Myers \& K. St. Louis (Eds.), Cluttering: A clinical perspective (pp. 3753). Far Communications. (Reissued in 1996 by Singular Press)

St. Louis, K., Myers, F., Bakker, K., \& Raphael, L. (2007). Understanding and treating cluttering. In E. Conture \& R. Curlee (Eds.), Stuttering and related disorders of fluency (pp. 297325). Thieme.

St. Louis, K., Myers, F., Cassidy, L., Michael, A., Penrod, S., Litton, B., Coutras, S., Olivera, J., \& Brodsky, E. (1996) Efficacy of delayed auditory feedback for treating cluttering: Two case studies. Journal of Fluency Disorders, 21, 305-314 https://doi.org/10.1016/S0094-730X(96)00033-2

St. Louis, K., Raphael, L., Myers, F., \& Bakker, K. (2003). Cluttering updated. The Asha Leader, 8-21, 4-5 \& 20-23. https://doi.org/10.1044/leader.FTR1.08212003.4

St. Louis, K., \& Scaler Scott, (2021). Cluttering guidelines. The Stuttering Foundation. www.StutteringHelp.org.

St. Louis, K., \& Schulte, K. (2011). Defining cluttering: The lowest common denominator. In D. Ward \& K. Scaler Scott (Eds.), Cluttering: Research, intervention, education. Psychology Press.

St. Pierre, J. (2012). The construction of the disabled speaker: Locating stuttering in disability studies. Canadian Journal of Disability Studies, 1(3), 1-21. https://doi.org/10.15353/cjds.v1 i3.54

Scaler Scott, K., \& St. Louis, K. (2011). Self-help and support groups for people with cluttering. In D. Ward \& K. Scaler Scott (Eds.), Cluttering: A handbook of research, intervention and education (pp. 211-229). Psychology Press.

Scaler Scott K., Tetnowski J., Roussel N., \& Flaitz J. (2007), Impact of a pausing treatment strategy upon the speech of a clutterer-stutterer. In K. Bakker, L. Raphael, \& F. Myers (Eds). Proceedings of the First World Conference on Cluttering. Katarino, Bulgaria (pp. 132-140).

Scaler Scott, K., Ward, D., \& St. Louis, K.O. (2010). Cluttering in a school-aged child. In S. Chabon and E. Cohn (Eds.). Communication disorders: A case-based approach: Stories from the front line. Allyn \& Bacon.

Sheridan, T. (1762). A course of lectures on elocution: Together with two dissertations on language and some other tracts relative to those subjects. London (Reprinted in 1974 by Scholar press).

Simkins, L., Kingery, M., \& Bradley, P. (1970). Modification of cluttered speech in an emotionally disturbed child. The Journal of Special Education, 4(1), 81-88. https://doi.org/10. 1177/002246697000400109

Simmons-Mackie, N. (2000). Social approaches to the management of aphasia. In L. Worrall, \& C. Frattali (Eds.), Neurogenic communication disorders: A functional approach (pp. 162187). Thieme.

Simpson, S. (2016). Stammering activism and speech-language therapy: An inside view. Did I stutter? https://www.didistutter. 
org/blog/stammering-activism-and-speech-language-therapyan-inside-view

Tetnowski, J., (2014). Stuttering and disability: Introduction to a panel discussion for consumers. [Conference Paper] Annual Conference of the National Stuttering Association, Washington, D. C.

Thelwall, J. (1812). Selections for the illustration of a course of instructions on the rhythmus and utterance of the English language: with an Introductory essay on the application of rhythmical science to the treatment of impediments, and the improvement of our national oratory; and an elementary analysis of the science and practice of elocution, composition, \&c. J. M'Creery.
Torraco, R. (2016). Writing integrative reviews of the literature: Methods and purposes. International Journal of Adult Vocational Education and Technology, 7(3), 62-70. https:// doi.org/10.4018/IJAVET.2016070106

Van Riper, C. (1992). Foreword. In F. Myers \& K. St. Louis (Eds.), Cluttering: A clinical perspective (pp. 7-9). Far Communications (Reissued in 1996 by Singular Press).

Van Zaalen, Y. \& Reichel, I. (2014). Cluttering treatment: Theoretical considerations and intervention planning. Perspectives on global issues in communication sciences and related disorders, 4(2), 57-62. https://doi.org/10.1044/gics4.2.57

Weiss, D. (1964). Cluttering. Prentice Hall.

Weiss, D. (1967). Cluttering. Folia Phoniatrica, 19(23), 233-263. 